\title{
Comparative ageing research: a flourishing field in need of theoretical cultivation
}

\author{
Clemens Tesch-Römer • \\ Hans-Joachim von Kondratowitz
}

Published online: 31 August 2006

(C) Springer-Verlag 2006

\begin{abstract}
Comparative ageing research is a flourishing field, partly because of European funding in this area. Comparing different societies and cultures seems especially fruitful for the analysis of societal and cultural factors in development over the life course. From a nomothetic perspective, the aim of comparisons is the search for similarities and communalities in different societies and cultures; from an idiographic perspective, researchers are looking for societal and cultural specificity and distinctiveness. However, the potentials of comparative ageing research are not fully realized for the time being. In many cases, there is little theorizing as to whether there should be differences (or similarities) in ageing processes across countries, societies, or cultures. This paper discusses theoretical aims and ambitions of comparative ageing research in general. Comparative theories are sketched which could serve as a basis for comparative ageing research, and ageing theories are discussed which could be modified to be used in comparative research. The rationale of comparative ageing research is described and illustrated through empirical examples. Epistemological and methodological pitfalls (problems of conceptual, operational, functional, and measurement equivalence) are a substantial obstacle to comparative ageing research. Hence, merits and limitations of comparative designs and sampling procedures are considered.
\end{abstract}

C. Tesch-Römer · H.-J. von Kondratowitz

German Centre of Gerontology, Berlin, Germany

C. Tesch-Römer ( $₫)$

Deutsches Zentrum für Altersfragen,

Manfred-von-Richthofen-Straße 2,

12101 Berlin, Germany

e-mail: tesch-roemer@dza.de
Keywords Comparative research - Cross-cultural comparisons $\cdot$ Theory $\cdot$ Methodology $\cdot$ Culture

\section{Introduction}

In the beginning of the twenty-first century, scientific policy at the European level stimulated comparative ageing research in Europe. This impetus was the practical political result of ongoing processes in academic disciplines as well as in society, all of which have shaped the comparative agenda. Increasing interest in comparing the achievement level of European welfare states, the impact of different socio-economic conditions on the living situation of the ageing populations, but also a higher degree of data availability for the purpose of comparison have all given such a research agenda the appropriate frame of reference. Very generously, the key action "Ageing Population" within the Fifth Framework Programme of the European Union (and to a much lesser extent also the Sixth Framework Programme) has provided funding for ageing research in Europe. This funding has lead prototypically to projects with participants from several European countries and associated nations, representing societies from Northern, Southern, Western, Eastern, and Central Europe. Quite a number of these projects conducted surveys or studies across participating countries. Hence, data sets were created which allow comparisons between nations, societies, and cultures.

However, although the scientists brought together in these research projects were specialists in their fields of gerontology, they often found themselves asking questions on the why and how of comparative ageing research (among them were the two authors of this 
paper). We believe that the current state of comparative ageing research can be likened to a garden full of wild flowers: empirical data sets are flourishing well, but the fields may be in need of some theoretical cultivation. To this extent, the present situation seems to reflect once more the crucial rift between theoretical reasoning and empirical research which has always characterized the social gerontological field and has been deplored on numerous occasions (e.g. Bengtson et al. 1999). In this conceptual paper, we would like to initiate a theoretical discourse about the possibilities, prerequisites and limits of comparative ageing research. Reflecting our own disciplinary background, we emphasize concepts and theories from psychology, sociology, and political science, but we believe that our arguments are feasible to comparative ageing research in other academic disciplines as well.

This paper has four parts. First, we discuss the aims, ambitions and current state of comparative ageing research in general. Second, some theoretical conceptions are sketched which might serve as a basis (or at least as "role models") for comparative ageing research. Thirdly, we present some examples of theoretically based comparative ageing research. Finally, we examine epistemological and methodological problems and limitations of comparative designs.

\section{Aims, ambitions and current state of comparative ageing research}

The phase of old age is part of the life course, and ageing processes are a subgroup of developmental changes. Individual development over the life course, and especially age related changes in late phases of life, are not fully explained by endogenous factors like biological maturation and functional decline. Hence, within different disciplines like life-span psychology and life-course sociology, but also epidemiology, conceptions of development and ageing have been established which point to the societal, cultural and historic embeddedness of change processes in adulthood and old age (e.g. Baltes 1987, 1997; Ben-Shlomo and Kuh 2002; Brandtstädter 1998; Kuh et al. 2003; Mortimer and Shanahan 2003; Settersten 2006). In addition, ageing research encompasses how developmental changes over the life course materialize in social positions and the social capital of specific age groups and how this impact in turn transforms given institutional settings within society. Comparing different societies and cultures seems especially fruitful for the analysis of societal and cultural factors in life course development (Fry 1996).
Comparative ageing research may be directed towards two-complementary or conflicting-main goals (Przeworski and Teune 1970; Ragin 1987; Daatland and Motel-Klingebiel 2006). From a nomothetic perspective, the aim of comparisons is the search for similarities and communalities in different societies and cultures. Questions relating to the similarity of ageing phenomena or determinants of change processes are examples of this perspective. Ultimately, this perspective aims to identify "anthropological universals" in ageing which materialize regardless of historical time and geographical space. Examples for universals might be seen in biological processes which proceed similarly across cultures and societies (e.g. skin wrinkles and greying hair). On the other hand, from an idiographic perspective researchers are looking for societal and cultural specificity and distinctiveness. In this perspective, differences between societies and cultures in respect to ageing processes are emphasized. The goal of this perspective is the identification of a societal and cultural frame for unique patterns of ageing processes. In this perspective, ageing is not an autonomous, time bound process, but is intertwined with societal institutions and cultural norms. Examples of culture specific patterns of ageing are retirement regulations and family solidarity in late life.

Despite the obvious differences, both perspectives refer to societal and cultural aspects of ageing. Although the constructs of "society" and "culture" are not independent of each other, they point to different systems. With the concept "culture" we refer to everyday practices, knowledge and belief systems as well as behaviour patterns which are used by members of a given population (cf. Berry 2000). With the concept of "society" we refer to those structures, institutions, and law systems which regulate as social facts and matters the behaviour of members of a given population. Societal structures and cultural belief systems are bound together in a complex nexus of interactions which do not always correspond harmoniously (e.g. cultural beliefs about ageing and old age could be in conflict with institutional retirement rules). However, both societal structures as well as cultural belief systems are relevant to ageing and old age. It should be kept in mind, however, that the definitions of culture and society also depend on the theoretical context (and might slightly vary from the definitions discussed here).

A framework for comparative ageing research can be found in cultural anthropology. The basic premise of anthropology is to study "humans at all times in all places" (Fry 1988). As humans are neither exclusively biological beings nor solely cultural constructions, human behaviour and development is shaped both by 
biology and culture. Hence, anthropological theory is holistic (emphasizing contexts), comparative (looking at a sample of the 3,000 \pm cultures worldwide), and evolutionary (taking into account the long history of mankind). In so doing, anthropological theory is striving to identify both universals of ageing and unique experiences of ageing. The methodology of cross-cultural studies also originated in anthropology (Murdock and White 1969). An early example of anthropology is the work of Simmons (1945), who analysed the status of ageing and old people in non-industrialized cultures. Simmons could not identify strong relations between economic, social, and political organization or religious beliefs with the status of old persons. Hence, this early work of cultural anthropology pointed to the influence of cultural and societal characteristics on the living situations of old people as complex, diverse, and context specific (Fry 1999).

Despite of these ambitions, the current state of comparative ageing research seems to be characterized by little theorizing as to whether (and why) there should be differences (or similarities) in ageing processes across countries, societies, or cultures. In the first issue of the European Journal of Ageing (December 2004), results from a variety of European projects have been published, and most of them have used the method of cross-cultural surveys (e.g. CLESA, ENABLE AGE, ESAW, EURODEP, FAMSUP, MOBILATE, OASIS, and SHARE). Although all of these projects involved four to eleven European countries, explicit a priori hypotheses about differences (or similarities) across societies and cultures are hardly to be found. More often, a posteriori reasoning is presented.

Just to give a few examples: Motel-Klingebiel et al. (2004) analysed the influence of social inequality on subjective quality of life in five countries and reported only small country differences. In the discussion section, they stated that "these findings display a common characteristic of the societies analysed. This stability suggests specifically life course and not just cohort effects" (p. 13). Ferring et al. (2004) explored life satisfaction in six European countries, and stated in the discussion section that "this study explores national, age, and gender differences in life satisfaction ratings. The findings ... are in line with previously reported findings" (p. 23) and later, the results were discussed with reference to the theoretical construct of societal "livability". Minicuci et al. (2004) reported on disabilityfree life expectancy in a cross-national perspective and explicated the hypothesis, that there might be a "North-South gradient" (higher levels of disability in the South, p. 38). Only in the discussion section was this "North-South gradient" explained by "socio- economic and cultural differences" (country differences in educational level, in the meaning of dependency, and the availability of family help, p. 42). Mollenkopf et al. (2004) looked at mobility in later life in six European countries. Although country differences were found (see p. 52), there was no explicit theoretical account of these differences on the macrolevel. Börsch-Supan et al. (2005) presented a large study with eleven countries involving a wide variety of topics. Three topics were discussed in the paper, namely work disability insurance enrolment, volunteering, and self-assessed health. Although there were country differences in all dependent variables, there was little theoretical reasoning to account for them (in respect to disability insurance, the authors point to societal differences regarding the "ease and generosity" in eligibility rules, p. 248).

We should hasten to add that all of these examples have excellent theoretical sections on the particular phenomenon in question (i.e. quality of life, life satisfaction, disability, mobility, volunteering, and selfassessed health). However, theoretical arguments for selecting the countries represented in the projects as well as a priori hypotheses predicting and explaining cross-societal and cross-cultural differences (or similarities) are often lacking. Hence, in the following section, we would like to discuss how the theoretical foundation of comparative ageing research could be improved.

\section{Theoretical conceptions relevant for comparative ageing research}

Gerontologists have elaborated a variety of theories connecting societal macro- and individual micro-levels (i.e. individual life time and historical time) in life course conceptions (Dannefer 1999; Kuh et al. 2003; Riley et al. 1999). However, there is no real comparable wealth of theoretical ideas available in respect of theories relating to comparative ageing research (for an exception, see the above-mentioned work of cultural anthropology, e.g. Fry 1999, 2006). For the time being, however, we do not see a complete set of theories for comparative ageing research. Looking for a theoretical foundation of comparative research question, there are two possible solutions which are both connected with certain limitations: On the one hand, one could choose a genuine comparative theory (which normally does not explicitly refer to old age and ageing), or on the other hand one could choose a genuine ageing theory (however, most of them have a limited cross-cultural potential). 
In the following, we first discuss some criteria for theories used in comparative ageing research. We then sketch some general comparative theories which may be modified in respect to ageing and old age in order to guide comparative ageing research. After that, we discuss how genuine ageing theories may be modified in order to allow their use in comparative ageing research.

Criteria for theories used in comparative ageing research

In general, scientific theories strive to organize empirical findings in a frugal manner and allow empirical tests of concrete hypotheses (Salthouse 2006). Theories serve to organize future research in specifying relevant questions which should be answered in empirical research. In particular, theories also serve to answer questions regarding the causal nexus of ageing phenomena and the mechanisms by which a cause exerts its effect. In respect to comparative ageing research, this means that theories should not only be helpful in identifying the relevant ageing phenomena which can be assumed to vary (or stay constant) across cultures and societies. More important is the function of theories in explicating causal mechanisms for variation (or stability) of ageing processes across cultures and societies. Hence, if variation across societies and cultures is assumed, a theory should be able to link macro-level constructs, i.e. characteristics of cultures and societies, to micro-level outcomes, i.e. behaviour of ageing individuals, by specifying mediating and moderating factors on the meso-levels of societal institutions and cultural norms and belief systems. If similarity (or even universality) of ageing processes is assumed, a theory should be able to explain this invariance by pointing to general mechanisms which operate universally even in the face of cultural and societal specificity.

Hence, we see four general criteria a comparative ageing theory should fulfil in order to guide comparative ageing research. First, a comparative ageing theory should lead to research questions regarding differences or similarities in ageing processes across cultures and societies. Second, within a comparative ageing theory different levels of analysis should be distinguished (at least macro-levels like society and culture on the one hand and micro-levels like individual change processes on the other hand). Moreover, researchers should be enabled to describe societies or cultures along certain characteristics. Third, a comparative ageing theory should try to explicate how macro-level characteristics influence developmental conditions on the micro-level. Fourth, a comparative ageing theory should allow the formulation of empirically testable hypotheses.
Modifying comparative theories for ageing research

We selected three general comparative theories which meet the criteria outlined above: (a) theory of cultural syndromes, (b) theory of ecological systems, and (c) theory of welfare state comparison. As these theories originally did not intent to explain cultural and societal differences in ageing processes, we will elaborate ageing related implications.

\section{Theory of cultural syndromes}

The theory of "cultural syndromes" is a prototypical comparative theory directed at the explanation of differences between cultures (Triandis 1989, 1996), and is an example of the nomothetic perspective in comparative research. According to Triandis (1994), culture is a system of meanings shared by persons speaking a common language dialect, living in a specific geographic region, during a particular historic period. "Cultural syndromes" consist of shared attitudes, beliefs, norms, values and self-definitions found among members of a society. The link between the cultural macro-level and the individual micro-level could be conceptualized in the form of unconscious "cultural standards". Cultural standards are those forms of perception, thinking, evaluating, and acting which are considered to be "normal" and obvious among members of a certain culture (Thomas 2003). These culturally shared standards function as orientation rules of behaviour and become conscious only in the case of violation or transgression of those standards. Examples of those cultural standards are the seniority principle in greeting rituals or the rules of intergenerational solidarity within families (Daatland and Herlofson 2003).

Cultures can be described according to a variety of cultural syndromes. Examples are complexity, tightness/ looseness, and individualism/collectivism. Cultural complexity refers to the extent of differentiation in societal systems, e.g. written language, economy, size of settlements. Tight cultures have many rules, norms, and ideas about what is correct behaviour in different kinds of situations; tolerant (or loose) cultures have fewer rules and norms. In tight cultures, transgressions of a norm will be sanctioned more quickly and strictly, while in loose cultures such transgressions will be tolerated. The dimension of individualism/collectivism refers to the understanding of society members as individual persons (individualism) or as part of a social group, caste or class (collectivism). Triandis (1994) has suggested interactions between these three cultural syndromes. Individualism arises in complex and loose societies, collectivism in simple and strict societies. Hence, the (still rather) strict Japan of the 
twenty-first century has become less collectivistic due to the increase of societal complexity in the last decades. A similar approach for the description of cultural dimensions has been developed by Hofstede (2001).

Quite a lot of research has been conducted on the relationship between cultural syndromes and identity or selfconcept (Triandis and Suh 2002). At the level of the individual, the "individual self" (idiocentrism) and the "collective self" (allocentrism) correspond to the poles of individualism versus collectivism, respectively (Triandis and Trafimow 2001). The individual self is characterized by traits, states or behaviour pattern (e.g. "I am diligent", "I am intelligent", "I like to exercise"). The collective self is characterized by relations to other persons or social groups (e.g. "I am the daughter of X", "I am the husband of $\left.\mathrm{Y}^{\prime}\right)$. Individual and collective self are represented separately in long-term memory, and the situational context determines whether elements of the individual or collective self are activated. Moreover, the relationship between individual and collective self depends on the culture. In collectivist cultures, the dimensions of allocentrism and idiocentrism are not correlated, while in individualistic cultures the correlation between the two is negative (Triandis and Trafimow 2001). This shows the complex relationship between cultural macro-level and individual micro-level of identity and self-concept. However, as the notion of "cultural syndromes" is not inherently concerned with development and ageing, it is necessary to make additional assumptions about the role of cultural syndromes in the ageing process (e.g. one could assume that in collectivist cultures the self-concept of ageing persons might be more stable than in individualist cultures).

\section{Theory of ecological systems}

The theory of ecological systems by Bronfenbrenner (2000) is a significant approach in ecological research. Bronfenbrenner's point of departure is the conception of interlocking ecological systems which are differentially relevant for human development and which change over historical time (Bronfenbrenner 1979; Bronfenbrenner and Morris 1998). Bronfenbrenner distinguishes between four hierarchical levels of ecological systems, with the lower levels embedded in the higher levels: micro-, meso-, exo- and macro-system. The micro-system contains the fabric of relations between the developing person and her or his immediate social and physical environment (e.g. family at home, class room with teacher and other students in school, frail old persons in a nursing home). The mesosystem contains all micro-systems which are relevant to a person at a certain point in time (e.g. old age home and self-help group). The exo-system contains social and societal structures and institutions which frame the settings and exo-systems of an individual without membership of the person in all of these systems (e.g. supervision agencies for old age homes, social security system). The macro-system relates to the cultural basis of a society which is constituted by bodies of law as well as cognitive belief systems and normative value systems. In addition to these four hierarchical system levels Bronfenbrenner introduces a chronological axis ("chrono-system") which regulates individual biographies according to critical life events and status passages (see Bronfenbrenner 1999).

Development is triggered by the interaction of an active individual and those persons, objects, and symbols in his or her immediate environment ("proximate processes"), with interactions taking place over an extended time period (Bronfenbrenner 2000, p. 130). Bronfenbrenner has published mainly on development in childhood and youth since the early 1960s (e.g. Bronfenbrenner 1970). In the current context, two aspects of Bronfenbrenner's theory should be highlighted. First, the proximate processes located in the level of the micro-system are more important for individual development than structures and processes on the meso-, exo-, and macro-level. Exemplary evidence for this thesis can be found in child development: The maternal responsiveness of mothers is a better predictor for the problem behaviour of children than social class (Bronfenbrenner 2000, p. 131). Secondly, Bronfenbrenner points out that proximate processes relevant to development are influenced by context factors which might vary strongly between cultures and societies. Support for this thesis was found in the ground breaking studies comparing the USA, the (former) USSR and other societies regarding context factors on the macro-level, like quality of the school systems, social inequality, or the prevalence of victimization through crime (Bronfenbrenner et al. 1996). Even if Bronfenbrenner's ecological theory has not been applied often to development in adulthood and old age (for an exception, see Bronfenbrenner 1999), it seems heuristically fruitful to apply elements of this approach to comparative ageing research (e.g. analysing proximate environments like nursing homes across cultures and societies, hence taking into account cultural frames like norms of family solidarity or societal contexts like health and social care policies).

\section{Theory of welfare state comparisons}

Originating in political science, the approach of welfare state comparisons analyses the social security 
system of states and relates these to the action and behaviour of individuals. Hence, the question is how individuals fare over time in different types of welfare states. A first step in comparing welfare states has been the construction of „welfare state typologies”. In his books Esping-Andersen $(1990,2000)$ identifies the process of decommodification of the wage earner in relation to three theoretical typologies for welfare regimes and social policy in advanced capitalist nations. In a completely "commodified" society, it is the individual's position on the labour market alone which is connected to income and earning. Hence, in a commodified society the individual's position on the labour market depends on individual characteristics (e.g. skills and health) and features of the market (e.g. demand). In contrast, "decommodification" means that an individual is entitled to earnings independent of his or her position on the labour market. Welfare production is uncoupled from market processes. The extent of decommodification relates to the degree of protection from labour market risks (e.g. unemployment and illness) through social security systems. For instance, the generosity of a pension system reduces the need for old people to take part in the labour market.

Originally, Esping-Andersen (1990) described three different welfare state types: (a) the "liberal model", often related to the USA, but also to Canada, Australia and increasingly the United Kingdom with only a low degree of decommodification, (b) the central European "conservative-corporatist model" with a medium degree of decommodification combined with internal status differentiation which is indicative of Germany, France, Austria, and Italy, (c) the "social democratic model", as exemplified by the Scandinavian countries and particularly Sweden, where decommodification has been extended to universal solidarity. Decommodification is highly relevant for the living situation and the behaviour of ageing and old people. Pension systems, as part of decommodifying social policies, have an influence on labour market participation in middle adulthood. The employment rate of older workers ( 55 years and older) is quite high in "market liberal" countries like the UK as well as in "social democratic" countries like Sweden, and low in "conservative-corporatist" countries like Germany. The European project OASIS has shown in addition that Spain as a "Mediterranean welfare state model" shows even lower employment rates (Kondratowitz 2003). However, recent reappraisals of a "political economy of ageing" which was already widespread in gerontology in the eighties demonstrate that welfare state activities in the field of ageing have to take into account a much richer and more comprehensive theoretical modelling than the typology approach can offer (Walker 2005).

Although Esping-Andersen's classifications remain the most commonly used in distinguishing types of modern welfare states and offer a solid starting point in such analysis, they have been increasingly criticised. Southern European welfare states of the "Mediterranean type" are not considered to be an independent model, and the Eastern European "transformation states" did not exist when EspingAndersen developed his original position. Moreover, the role of the family and women in particular as highly important producers of welfare and the consequences of gendered division of labour in the care for children and elders have been neglected (Lessenich and Ostner 1998). This criticism has lead to new typologies, for instance to a model which differentiates welfare states according to "care regimes". In this typology, welfare states are categorized by the extent to which they have established gender equality in the systems of employment and (child) care (Lewis 2002). This approach would enable the analysis of the cultural foundations of welfare production (Chamberlayne et al. 1999). Finally, the welfare state approach only partly spells out the mediating mechanism which relates the macro-level characteristics of a "welfare state model" to the individual behaviour of an ageing person. It would be a challenging task to accomplish in the future.

\section{Modifying ageing theories for comparative research}

Although we believe that the theories described above are potentially important for comparative ageing research, we are aware that these theories are by no means exhaustive in respect to possible theoretical questions raised in comparative ageing research. However, many successful theories in gerontology have been formulated without the focus on comparative ageing research (see for an overview, Bengtson and Schaie 1999). It could be even said that many, if not most theories of ageing explicitly or implicitly claim universal validity (e.g. theories regarding memory or intelligence development over the life course, biological theories of ageing), but the universality of ageing theories is not always tested using comparative research designs. Moreover, it could be productive to modify "general" ageing theories with respect to cultural and societal differences. Gerontological theories might be extended with additional assumptions in order to guide comparative ageing research. Three theories might serve as examples. 


\section{Disengagement theory}

Despite the long history of criticism of disengagement theory, the approach of Cumming and Henry (1961) still is an excellent example for theoretically linking macro-structure (retirement regulation) and microlevel (retirement behaviour, life satisfaction). Disengagement has been defined as "an inevitable process in which many of the relationships between a person and other members of society are severed, and those remaining are altered in quality" (Cumming and Henry 1961, p. 210). In other words, it involves the process of social and psychological withdrawal of an individual from society. Disengagement is theorized to result in a reduction of life activities and ego energy in old age. Although disengagement theory was formulated as a general, almost universal theory, there is also reference to differences across cultures and societies (e.g. "disengagement is a culture-free concept, but the form it takes will always be culture bound", p. 218). Hence, in order to use disengagement theory for comparative ageing research it would be necessary to explicate the societal and cultural conditions which influence the processes of disengagement (e.g. type and formality of retirement regulations, existence and kind of social security systems).

\section{Dual-process model of developmental regulation}

The dual process model of developmental regulation (Brandtstädter 1998; Brandtstädter and Rothermund 2002) conceptualizes the management of developmental goals. Developmental goals motivate a person, give a structure to everyday life and are the basis for personal identity and meaning of life. The interaction between "tenacious goal pursuit" (or assimilative processes) and "flexible goal adjustment" (or accommodative processes) is phylogenetically rooted in the architecture of the human psyche. Hence, these processes can be interpreted as universals of human development (Brandtstädter and Rothermund 2002, p. 141). However, also in this approach development, culture, and action are intimately related. Culture constitutes action spaces which shape the opportunities and meanings of developmental actions (Brandtstädter 1998). For the pursuit of developmental goals and the management of blocked goals tenacity and flexibility are relevant in all cultures, but the specific forms of these regulatory processes and their dynamics may vary between cultures. Even if this model does not make explicit statements about cultural differences, one can formulate additional assumptions. It could be hat cultural beliefs and norms in respect to coping with blocked goals might differ across cultures (in individualistic cultures assimilative tendencies might be stronger, while in collectivistic cultures accommodative tendencies might prevail; cf. Tesch-Römer 2005).

\section{Socio-emotional selectivity theory}

Socio-emotional selectivity theory (Carstensen 1995; Carstensen et al. 2006) claims that the perception of time plays a fundamental role in the selection and pursuit of social goals. According to this theory, social motives fall into one of two general categories-those related to the acquisition of knowledge and those related to the regulation of emotion. When time is perceived as open-ended, knowledge-related goals are prioritized. In contrast, when time is perceived as limited, emotional goals assume primacy. The inextricable association between time left in life and chronological age ensures age-related differences in social goals. As social motives change over the life course, there is a stronger preference for intimate relations in later life. If one adds to this theory the assumption that these changes in motivation are "anthropological universals", one could test this hypothesis cross-culturally. An example for an empirical test of socio-emotional selectivity theory in comparative research is the analysis of age differences in social preferences among Taiwanese and Mainland Chinese (differences between the two cultures disappear when differences in perceived time were statistically controlled for; Fung et al. 2001).

\section{Resume}

Summarizing, we believe that it is possible to improve the theoretical foundation of comparative ageing research. First, there are general comparative theories available which might be used in comparative ageing research (some examples are listed above). Second, it seems possible to extend existing gerontological theories for comparative ageing research. Next, we explicate the rationale for conducting comparative ageing research and illustrate this with some examples.

\section{Rationale for conducting comparative ageing research and some examples}

As mentioned before, scientific theories help to organize the empirical cycle: formulating research questions, describing phenomena in question, deriving and testing hypotheses, and organizing findings as parsimonious as possible. Taking together the arguments outlined so far, we believe that four steps are necessary 
in order to pursue comparative ageing research driven by theoretical conceptions. After describing the four steps of the research cycle in general, we will give some concrete examples from current publications.

Formulate a research question In a first step, it is necessary to formulate a research question regarding cross-cultural and cross-societal similarities and differences of a particular ageing phenomenon. Can we expect that ageing trajectories are similar (or even equal) under diverse societal or cultural conditions or do we expect differences (and why)?

Distinguish and describe levels of analyses In a second step, it is necessary to distinguish the relevant levels of analysis (e.g. regions, nations, states, societies, or cultures on the macro-level; institutions or organizations on the meso-level; behaviour of individuals or groups on the micro-level). It is also highly important to identify and describe cultural and societal dimensions. One should use universal dimensions for these descriptions (e.g. societal wealth, type of social policy, cultural norms), and locate various cultures and societies on these dimensions. Rarely, the selection of macro-level units is a random process (resulting in a large number of cultures or societies). More often, especially in a European context, the number of macro-level units is small. Hence, the choice of macro-level units should be driven by theory (Ebbinghaus 2005).

Explicate mechanisms In a third step, one has to explicate the mechanisms which relate the macro-level with the meso-level of institutions or organizations, respectively, with the micro-level of individual or group behaviour. At this point, it is decisive to rely on knowledge about the cultures and societies in question in order to understand the mechanisms which relate macro-, meso-, and micro-levels in different cultures and societies. If universality of ageing processes is assumed, this invariance should be explained by pointing to general mechanisms which operate regardless of cultural and societal uniqueness.

Generate hypotheses Finally, in a fourth step, hypotheses in respect to the relation between cultural belief and value systems or societal structures and individual behaviour should be formulated. These hypotheses should be formulated a priori, and they should be falsifiable with empirical data.

After having described these steps in a general manner, we would like to illustrate them using published research. Those examples of comparative ageing research show in our view that a theoretical foundation for cross-cultural and cross-societal comparisons is highly productive. It should be kept in mind, however, that instead of these examples other instances of theoretically based ageing research could have been chosen as well.

Braam et al. (2004) examined in the "EURODEP Concerted Action" whether the association between disability and depressive symptoms is modified by societal characteristics which differ across European countries. EURODEP started from the observation that disability is a main determinant of depressive symptoms in late life. Hence, it was asked if contextual factors like the availability of mental health care would modify this relationship (Step 1: research question). The macro-level units in this study were European countries. They were described according to four dimensions (health care, economic wealth, demographics, and religious tradition measured by 13 indicators). The countries were chosen in order to represent a "considerable cross-national variety of contextual factors" (p. 27). The micro-level units were individuals (Step 2: levels of analyses). Regarding the link between macro- and the micro-levels, the authors stated, that "the association between physical health and depression is less pronounced with better health care facilities available" (p. 33). Hence, the authors pointed to the mechanisms which are responsible for the modifying effect of health care infrastructure (Step 3: mechanism). Finally, the authors formulated hypotheses (or rather research questions, p. 27) and reported on confirmed (and falsified) hypotheses (p. 33; Step 4: hypotheses).

Attias-Donfut et al. (2005) analysed the intergenerational flow of gifts and support in ten European countries. The starting point of the analysis of data from the "Survey of Health, Ageing, and Retirement in Europe" (SHARE) was the observation that cash gifts flow from the older to the younger generation while time gifts come from the younger to the older generation. It was asked if this pattern of intergenerational support is similar or different across European countries (Step 1: research question). The levels of analyses were countries on the macro-level, and individuals on the micro-level. The authors stated that along a NorthSouth gradient there are national differences in culture (e.g. family norms), demographics (e.g. family structures), and political history (e.g. type and degree of welfare systems) which may influence the intergenerational exchange of support. The selection of ten European countries was justified by reference to the work of Esping-Andersen (Step 2: levels of analyses). In respect to financial transfers, the authors argued, that 
in countries with generous pension schemes older people should make more financial transfers because they have more resources to give (p. 162, Step 3: mechanism). Finally, the authors formulated and empirically tested hypotheses about similarities and differences between countries in intergenerational exchange of support (p. 162, 170). The authors predicted similarities across countries for direction of transfers, and differences between countries for rate of financial transfers and amounts of time and money exchanged (Step 4: Hypotheses).

Motel-Klingebiel et al. (2005) looked at the relationship between family support and formal services provided by the welfare state, using data from the project "Old Age and Autonomy: The Role of Service Systems and Intergenerational Family Solidarity" (OASIS). They started with the question whether welfare states "crowd out" family support by providing social services (Step 1: research question). Levels of analyses were countries on the one hand, and individuals on the other hand. The five countries (Norway, England, Germany, Spain, Israel) were described according to Esping-Andersen's typology of welfare state, adding the categories "residual welfare state" (for Spain) and "mixed model" (for Israel). The main dimension used in the description of macro-level units was the notion of "generosity" of welfare state provision (Step 2: levels of analyses). In analysing the macro-micro-link, the authors considered the availability of support from the state as well as from the family, highlighting the relevance of family structures as well as norms and preferences for intergenerational support (Step 3: mechanism). Finally, three alternative hypotheses were formulated regarding the relation between family support and formal services (substitution, mutual encouragement, mixed responsibility). These hypotheses were tested empirically, showing that family structures as well as preferences and norms in respect to support confirmed the hypothesis of mixed responsibility of family support and formal services (Step 4: hypotheses).

\section{Epistemological and methodological problems of comparative ageing research}

Comparative ageing research not only can be improved by choosing adequate theoretical foundations, but also by tackling epistemological and methodological problems which are connected to comparative research in general. In the following we will stress (a) epistemological essentials in this area, (b) the problem of equivalence, and (c) the question of levels of analyses.
Epistemological problems

In the beginning, we distinguished between "nomothetic" and "idiographic" perspectives (searching for commonalities resp. differences across cultures and societies). This distinction relates to the difference between "emic" and "etic" research perspectives, originating in linguistics (Pike 1954). The emic (or idiographic) perspective focuses on culture specific concepts and constructs which are meaningful for the members of a society (e.g. the belief of certain cultures that there is a "supra-natural" world above and beyond the "natural" world). The etic (or nomothetic) perspective relates to concepts and constructs which are not inherently tied to a certain culture and which can be described from the outside by external observers (e.g. the energy consumption per person of a society).

Both perspectives have merits (and problems). While the emic perspective allows the exploration of culture from within, in its own right, it is difficult to formulate standards of comparisons which might enable comparisons between cultures. Just the opposite is true for the etic perspective, which supports the construction of comparative dimensions, but may overlook the particularity and uniqueness of a culture. Emic researchers have criticized the apparent objectivity and neutrality of the etic perspective and emphasized the need for indigenous analyses (see, for instance, the debate between "cultural psychology" and "comparative psychology", Eckensberger and Plath 2003; Triandis and Marin 1983). However, we believe that these two perspectives are not incompatible (Headland et al. 1990; Poortinga 1992). The goal of comparative research-relating variations in cultures and societies to similarities and differences in the behaviour of individuals (etic perspective) - has to be combined with precise and deep knowledge about the specific cultures and societies (emic perspective), in order to avoid ethnocentric fallacies.

An example for the emic interpretation of findings based on etic analyses can be found in the work of Minicuci et al. (2004). In their analyses of country differences in life expectancy free of disabilities (higher in northern than in southern countries), the authors note that disability and the connected need for help in northern countries is seen as individual weakness (information which has to be withhold from other persons) while in southern countries family interdependence is highly valued (and, therefore, older adults openly communicate about frailty and need for help). Hence, differences in disability rates between countries may stem not only from varying socio-economic wealth of societies, but also from cultural-specific communication 
about frailty as well. Hence, the authors conclude, that it is necessary "to evaluate differences in self-reported ADL and how it is influenced by cultural norms in order to make this measurement a sound indicator of need for services" (Minicuci et al. 2004, p. 42/43).

\section{Problems of equivalence}

Closely linked to the etic and emic perspective is the problem of comparability of behavioural and psychological phenomena. In order to compare cultures and societies, a standard of comparison which is valid in all cultures and societies to be analysed needs to be created (Hui and Triandis 1985). Hence, behavioural, psychological, and medical phenomena have to be conceptualized, described, and measured in a manner that is equivalent across cultures and societies (again, this seems possible only by combining etic and emic perspectives). First, it has to be elaborated that there are (universal) dimensions which are useful for comparing cultures and societies (etic perspective). Indigenous knowledge about culture and society are necessary to evaluate the adequacy of the (universal) dimension in question (emic perspective).

Especially important is the translation problem. Is it possible to convert a culturally meaningful word into another language? The translation problem and the possibility of transferability of meaning have been discussed in linguistics and philosophy of language under the umbrella of the Sapir-Whorf hypothesis (Sapir 1921; Whorf 1956). Briefly, this hypothesis states the following: If language constitutes and limits the ways people think, then translation between languages has to relate to the specific contexts of the language of origin into the language of destination, in order to create equivalent constructions of meaning-otherwise a translation is not possible. Quite often, the problem of linguistic equivalence is tackled by the method of translation and re-translation (one person translates a questionnaire from language $\mathrm{A}$ into language $\mathrm{B}$, a second person re-translates the language $B$ version of the questionnaire back into language $\mathrm{A}$; the differences between the original and the re-translated version are used to correct the translated version, etc.). Although this method is often used, it is by no means certain that both versions of an instruments are equivalent in languages $\mathrm{A}$ and $\mathrm{B}$, because both in the processes of translation and re-translation analogous shifts of meaning may occur and hide the change of meaning in the two versions. Probably, a better alternative for reaching equivalence is an extended discourse process. Scientists involved in comparative projects should discuss a particular construct (e.g. happiness). In this discourse process "indigenous" perspectives of persons who are well acquainted with the cultures $\mathrm{A}$ and $\mathrm{B}$ have to be represented, and contexts for the construct in question have to be detailed. It has to be taken into consideration, though, that only rarely do truly bilingual researchers take part in comparative projects, and that-at least in the European context-most debates in comparative projects are held in English (and hence, the translation process quite often involves three languages: language $\mathrm{A} \rightarrow$ English $\rightarrow$ language $\mathrm{B}$, and vice versa). Hence, research consortiums should devote enough time for the thorough discussion of theoretical concepts with respect to the cultures represented in the research consortium.

Methodologically, the translation problem is connected to several aspects of equivalence: conceptual, operational, functional, and measurement equivalence (Helfrich 2003). Conceptual equivalence means that a concept of interest is identical (or at least comparable) across cultures and languages. If a comparative research question involves the concepts "quality of life" or "aggression" it has to be ensured that these concepts exist in all cultures and languages of interest. Operational equivalence relates to indicators which are used to measure non-observable concepts. One can assume operational equivalence if the same indicators can be used across cultures and languages. This is the case, e.g. if "positive affect" and "satisfaction" can be used in different languages to measure the concept "quality of life". It might be the case, however, that in different cultures different indicators are used for the same underlying concept. If different indicators tap the same concept, the indicators are functionally equivalent. While verbal insults might be interpreted as aggressive behaviour in one culture, this could apply to some types of gifts in another. Hence, in this example "verbal insults" and "special gifts" are functional equivalent (Trommsdorff 1978). Finally, the instruments used in research projects as well as the settings of interviewing or testing could differ across cultures. It has to be ensured that the measurement conditions are similar across culture and societies.

Levels of analysis and sampling

In comparative ageing research, it is indispensable to distinguish levels of analysis. Quite often, the main interest is the distinction between collective levels (culture, society) and individual levels (behaviour and emotions of a person), but the analysis of meso-levels (institutions, organizations) might be of interest as well. On the collective level, macro-factors are responsible for similarities and differences between cultures 
and societies. On the individual level, micro-factors which are embedded in macro-structures influence the behaviour of people. In comparative research, the minimum number of levels is two (individuals on the first level, society/culture on the second level). However, this simplifies the complex relationships between levels. First, it is often unclear if the higher level refers to a geographically confined state with specific legal structures (e.g. "United Kingdom", "Federal Republic of Germany"), a nation, a society, or a culture. Secondly, within states and countries, quite often one can distinguish between distinct regional variations (e.g. England and Wales in the UK, Bavaria and NordrhineWestfalia in Germany). The theoretically based distinction of relevant levels of analysis has to be distinguished from the statistical analysis of multi-level data (statistical analysis of multi-level data is not discussed in this paper, see Bingenheimer and Raudenbush 2004; Blakely and Woodward 2000; Raudenbush 1999 for a discussion).

Closely related to the problem of levels of analyses are the procedures and methods of sampling (collectives and individuals). The problem of case selection is a crucial but often overlooked issue in comparative cross-national research. In selecting macro-level units there is the problem of contingency, the fact that the potential pool of cases has been pre-selected by historical and political processes. Hence, although often regarded as necessary, comparative studies with large numbers of macro-level units are not always required. If only a small number of macro-level units are chosen, this choice should be based on theoretical considerations (Ebbinghaus 2005).

While cultures and societies might be chosen for theoretical reasons, the persons sampled within societies and cultures should be comparable. Using different methods of sampling in different countries could lead to confounding effects. For instance, if one samples in a "collectivistic" culture only from the rural population, and from an "individualistic" culture only from the urban population, culture (collectivistic/individualistic) and type of settlement (rural/urban) are confounded. Matched samples should also be avoided as the confounding variables could systematically co-vary with the variable of theoretical interest (Helfrich 1999). If researchers are interested in comparing the general population across cultures and societies, random population samples should be chosen instead of matched (occasional) samples. However, even this might be difficult because countries differ in the understanding of what the state should know about their citizens. For instance, as there is no official registry of citizens in the UK, other routines have to be followed in sampling (e.g. random route sampling) as compared to Germany where municipality registries exist (and random sampling from registers is possible). The meticulous planning of sampling should be complemented by a thorough analysis of fundamental socio-demographic and status variables (e.g. distribution of age, gender, education) and the comparison between sample characteristics and national statistics (Motel-Klingebiel et al. 2003).

\section{Outlook}

In this conceptual paper we have tried to show that it is possible, rewarding, and productive to advance comparative ageing research by choosing an adequate theoretical foundation. Comparative ageing research aims at describing and explaining the differences and similarities in thinking, emotion, and behaviour of ageing and old individuals living in diverse cultures and societies. This type of research strives to test the universality or cultural specificity of hypotheses and theories. Hence, the contexts of human development over the life course are of central relevance in this context. To realize such a demanding program, research projects have to be well planned and sufficiently financed. Moreover, comparative projects should involve expertise from diverse fields and disciplines. In any case, however, researchers are well advised to cooperate with political scientists or anthropologists familiar with comparative research. Theoretical and methodological problems have to be discussed thoroughly, and decisions with their consequences have to be understood by all participating scientists. However, this requires more time and effort as normally invested (and a "normal" project can be time consuming and exhaustive, already). In addition, members of international research groups have to be aware of specific communication problems, which may reflect cultural differences as well. Nevertheless, the promise of theoretical advancement of gerontology as well as the hope for culture specific interventions is combined with personal fulfilment in learning about cultural differences and similarities. Summarizing, we believe that theoretically based comparative ageing research is a promising area and should be pursued even more than it is the case at present. We hope that we were able to point to some requirements for comparative ageing research and hope that an ensuring discourse will help to cultivate a flourishing and growing field.

Acknowledgments We would like to thank the editors of the European Journal of Ageing, Dorly Deeg and Hans-Werner Wahl, who encouraged us to start (and finish) this paper. In this process, they generously shared their experience and ideas with us. 


\section{References}

Attias-Donfut C, Ogg J, Wolff FC (2005) European patterns of intergenerational financial and time transfer. Eur J Ageing 2:161-173

Baltes PB (1987) Theoretical propositions of life-span developmental psychology. On the dynamics between growth and decline. Dev Psychol 23:611-626

Baltes PB (1997) On the incomplete architecture of human ontogenesis: Selection, optimization, and compensation as foundation of developmental theory. Am Psychol 52:366-381

Bengtson VL, Schaie KW (eds) (1999) Handbook of theories of aging. Springer, Berlin Heidelberg New York

Bengtson VL, Rice CJ, Johnson ML (1999) Are theories of aging important? Models and explanations in gerontology at the turn of the century. In: Bengtson VL, Schaie KW (eds) Handbook of theories of aging. Springer, Berlin Heidelberg New York, pp 3-20

Ben-Shlomo Y, Kuh D (2002) A life course approach to chronic disease epidemiology: conceptual models, empirical challenges and interdisciplinary perspectives. Int $\mathbf{J}$ Epidemiol 31:285-293

Berry JW (2000) Culture. In: Kazdin AE (ed) Encyclopedia of psychology. Oxford University Press, New York, pp 392-400

Bingenheimer J, Raudenbush SW (2004) Statistical and substantive inferences in public health: issues in the application of multilevel models. Ann Rev Public Health 25:53-77

Blakely T, Woodward A (2000) Ecological effects in multi-level studies. J Epidemiol Community Health 54:367-374

Börsch-Supan A, Hank K, Jürges H (2005) A new comprehensive and international view on aging: introducing the "survey of health, ageing, and retirement in Europe". Eur J Ageing 2:245-253

Braam AW, Delespaul P, Breekman ATF, Deeg DJH, Pérès K, Dewey M et al (2004) National context of healthcare, economy, and religion, and the association between disability and depressive symptoms in older Europeans: results from the EURODEP concerted action. Eur J Ageing 1:26-36

Brandtstädter J (1998) Action perspectives on human development. In: Lerner RM (ed) Handbook of child psychology: theoretical models of human development, vol 1, 5th edn. Wiley, New York, pp 807-863

Brandtstädter J, Rothermund K (2002) The life-course dynamics of goal pursuit and goal adjustment: a two-process framework. Dev Rev 22:117-150

Bronfenbrenner U (1970) Two worlds of childhood: U.S. and U.S.S.R. Russell Sage Foundation, New York, NY

Bronfenbrenner U (1979) The ecology of human development. Harvard University Press, Cambridge, MS

Bronfenbrenner U (1999) Environments in developmental perspective: theoretical and operational models. In: Friedman S, Wachs TD (eds) Measuring environment across the life span: emerging methods and concepts. American Psychological Association, Washington, DC, pp 3-28

Bronfenbrenner U (2000) Ecological systems theory. In: Kazdin AE (ed) Encyclopedia of psychology. Oxford University Press, New York, NY, pp 129-133

Bronfenbrenner U, Morris PA (1998) The ecology of developmental processes. In: Damon W (ed) Handbook of child psychology, vol 1 theory, 5th edn. Wiley, New York, pp 9931028

Bronfenbrenner U, McClelland P, Wetherington E, Moen P, Ceci SJ (1996) The state of Americans: this generation and the next. Free Press, New York

Carstensen LL (1995) Evidence for a life-span theory of socioemotional selectivity. Curr Dir Psychol Sci 5:151-156
Carstensen LL, Mikels JA, Mather M (2006) Aging and the intersection of cognition, motivation, and emotion. In: Birren JE, Schaie KW (eds) Handbook of the psychology of aging, 6 edn. Elsevier Academic, Amsterdam pp 343-362

Chamberlayne P, Cooper A, Freeman R, Rustin M (eds) (1999) Welfare and culture in Europe: towards a new paradigm in social policy. Jessica Kingsley Publ, London

Cumming E, Henry, WE (1961) Growing old: the process of disengagement. Basic, New York

Daatland SO, Herlofson K (2003) "Lost solidarity" or “changed solidarity". A comparative European view of normative family solidarity. Ageing Soc 23(5):537-560

Daatland SO, Motel-Klingebiel A (2006) Separating the local and the general in cross-cultural ageing research. In: Wahl HW, Tesch-Römer C, Hoff A (eds) Emergence of new personenvironment dynamics in old age. A multidisciplinary exploration. Baywood, Amityville, NY (in press)

Dannefer D (1999) Paths of the life course: a typology. In: Bengtson VL, Schaie KW (eds) Handbook of theories of aging. Springer, Berlin Heidelberg New York, pp 306-326

Ebbinghaus B (2005) When less is more. Selection problems in large- $\mathrm{N}$ and small-N cross-national comparisons. Int Sociol 20(2):133-152

Eckensberger L, Plath I (2003) Möglichkeiten und Grenzen des "variablenorientierten" Kulturvergleichs. Von der Kulturvergleichenden Psychologie zur Kulturpsychologie. In: Kaelble H, Schriewer J (eds) Vergleich und Transfer. Komparatistik in den Sozial-, Geschichts- und Kulturwissenschaften. Campus, Frankfurt, pp 55-99

Esping-Andersen G (1990) The three worlds of welfare capitalism. Polity Press, Cambridge

Esping-Andersen G (2000) Three worlds of welfare capitalism. In: Pierson C, Castles FG (eds) The welfare state. Malden, MA, pp 154-169

Ferring D, Balducci C, Burholt V, Wenger C, Thissen F, Weber $\mathrm{G}$ et al (2004) Life satisfaction of older people in six European countries: findings from the European study on adult well-being. Eur J Ageing 1:15-25

Fry C (1988) Theories of age and culture. In: Birren JE, Bengtson VL (eds) Emergent theories of aging. Springer, Berlin Heidelberg New York, pp 447-481

Fry CL (1996) Comparative and cross-cultural studies. In: Birren JE (ed) Encyclopedia of gerontology, vol I, A-K. Academic, San Diego, pp 311-318

Fry CL (1999) Anthropological theories of aging. In: Bengtson VL, Schaie KW (eds) Handbook of theories of aging. Springer, Berlin Heidelberg New York, pp 306-326

Fry CL (2006) The social construction of age and the experience of aging in the late twentieth century. In: Wahl HW, TeschRömer C, Hoff A (eds) New dynamics in old age: individual, environmental and societal perspectives. Baywood, Amityville, NY

Fung HH, Lai P, Ng R (2001) Age differences in social preferences among Taiwanese and Mainland Chinese: the role of perceived time. Psychol Aging 16:351-356

Headland T, Pike, KL, Harris M (eds) (1990) Emics and etics: the insider/outsider debate. Sage, Newbury Park

Helfrich H (1999) Beyond the dilemma of cross-cultural psychology: resolving the tension between etic and emic approaches. Cult Psychol 5:131-153

Helfrich H (2003) Methodologie kulturvergleichender psychologischer Forschung. In: Thomas A (ed), Kulturvergleichende Psychologie, 2nd edn. Hogrefe, Göttingen, pp 111-139

Hofstede G (2001) Culture's consequences: comparing values, behaviors, institutions and organizations across nations, 2nd edn. Sage, Beverly Hills, CA 
Hui H, Triandis HC (1985) Measurement in cross-cultural psychology: a review and comparison of strategies. J Cross-Cult Psychol 16:131-152

Kondratowitz HJv (2003) Comparing welfare states. In: Lowenstein A, Ogg J (eds) Old age and autonomy: the role of service systems and intergenerational family solidarity, Haifa University, Haifa, pp 25-62

Kuh D, Ben-Shlomo Y, Lynch J, Hallqvist J, Power C (2003) Life course epidemiology. J Epidemiol Community Health 57:778-783

Lessenich S, Ostner I (eds) (1998) Welten des Wohlfahrtskapitalismus. Campus, Frankfurt

Lewis J (2002) Gender and welfare state change. Eur Soc 4(4):331-357

Minicuci N, Noale M, Pluijm SMF, Zunzunegui MV, Blumstein T, Deeg DJH et al (2004) Disability-free life expectancy: a cross-national comparison of six longitudinal studies on aging. The CLESA project. Eur J Ageing 1:7-44

Mollenkopf H, Marcellini F, Ruoppila I, Széman Z, Tacken M, Wahl HW (2004) Social and behavioural science perspectives on out-of-home mobility in later life: findings from the European project MOBILATE. Eur J Ageing 1:45-53

Mortimer JT, Shanahan MJ (eds) (2003) Handbook of the life course. Kluwer/Plenum, New York

Motel-Klingebiel A, Tesch-Römer C, Kondratowitz HJv (2003) The quantitative survey. In: Lowenstein A, Ogg J (eds) Old age and autonomy: the role of service systems and intergenerational family solidarity. Haifa University, Haifa, pp 63-101

Motel-Klingebiel A, Kondratowitz, HJv, Tesch-Römer C (2004) Social inequality in old age-comparative views on quality of life of older people. EurJ Ageing 1:6-14

Motel-Klingebiel A, Tesch-Römer C, Kondratowitz, HJv (2005) Welfare states do not crowd out the family: evidence for mixed responsibility from comparative analyses. Ageing Soc 25:863-882

Murdock GP, White DR (1969) Standard cross-cultural sample. Ethnology 8:329-369

Pike KL (1954) Language in relation to a unified theory of the structure of human behavior. Summer Institute of Linguistics, Glendale, CA

Poortinga YH (1992) Towards a conceptualization of culture for psychology. In: Iwawaki S, Kashima Y, Leung K (eds) Innovations in cross-cultural psychology, Swets \& Zeitlinger, Amsterdam, pp 3-17

Przeworski A, Teune H (1970) The logic of comparative social inquiry. Krieger, Malabar

Ragin CC (1987) The comparative method: moving beyond qualitative and quantitative strategies. University of California Press, Berkeley
Raudenbush SW (1999) Hierarchical models. In: Kotz S (ed) Encyclopedia of statistical sciences, vol 3. Wiley, New York, pp 318-323

Riley MW, Foner A, Riley JWJ (1999) The aging and society paradigm. In: Bengtson VL, Schaie KW (eds) Handbook of theories of aging. Springer, New York, pp 327-343

Salthouse TA (2006) Theoretical issues in the psychology of aging. In: Birren JE, Schaie WK (eds) Handbook of the psychology of aging. Elsevier Academic, Amsterdam pp 3-13

Sapir E (1921) Language: an introduction to the study of speech. Hartcourt, Brace, New York

Settersten RAJ (2006) Aging and the life course. In: Binstock RH, Gerorge LK (eds) Handbook of aging and the social sciences, 6th edn. Elsevier Academic, Amsterdam, pp 3-19

Simmons L (1945) The role of the aged in primitive society. Yale University Press, New Haven, CT

Tesch-Römer C (2005) Universal accommodation? Cross-cultural notes on Brandtstädter's developmental theory of action. In: Greve W, Rothermund K, Wentura D (eds) The adaptive self: personal continuity and intentional self-development. Hogrefe, Göttingen, pp 285-297

Thomas A (2003) Psychologie interkulturellen Lernens und Handelns. In: Thomas A (ed) Kulturvergleichende Psychologie, 2nd edn. Hogrefe, Göttingen, pp 433-485

Triandis HC (1989) The self and social behavior in differing cultural contexts. Psychol Rev 96:506-520

Triandis HC (1994) Culture and social behavior. McGraw-Hill, New York

Triandis HC (1996) The psychological measurement of cultural syndromes. Am Psychol 51:407-415

Triandis HC, Marin G (1983) Etic plus emic versus pseudoetic: a test of a basic assumption of contemporary cross-cultural psychology. J Cross-Cult Psychol 14:489-500

Triandis HC, Suh EM (2002) Cultural influences on personality. Annu Rev Psychol 53:133-160

Triandis HC, Trafimow D (2001) Cross-national prevalence of collectivism. In: Brewer MB, Sedikides C (eds) Individual self, relational self, collective self. Psychology Press Philadelphia, PA, pp 259-276

Trommsdorff G (1978) Möglichkeiten und Probleme des Kulturvergleichs am Beispiel einer Aggressionsstudie. Kölner Z Soz Sozialpsychol 13:361-381

Walker A (2005) Towards an international political economy of ageing. Ageing Soc 25:815-839

Whorf BL (1956) Language, thought and reality. Wiley, New York 